\title{
Comparative and Socio-Demographic analysis among Working Women and Non-Working Women: A study on Reference Group Influence
}

\author{
Semila Fenelly Fernandes ${ }^{1}$, Rajesh Panda ${ }^{2}$ \\ \{semila.fernandes@sibm.edu.in ${ }^{1}$ director@sibm.edu.in $\left.{ }^{2}\right\}$ \\ Symbiosis Institute of Business Management, Bengaluru ${ }^{1,2}$
}

\begin{abstract}
Reference Group (RG) influence refers to conforming to group pressure which impacts consumers' product purchases. Studies on Reference Group Influence(RGI) varies from men to women while studies indicated that women are more prone to RGI. NonWorking Women (NWW) and Working Women (WW) differ in their buying pattern as they are susceptible to RG. RGI takes three forms: informational reference group(IRG), utilitarian reference group(URG) and value-expressive reference group(VERG). The current study compares and analysis the socio-demographic variables like age, education and household income (HI) and its impact on the susceptibility of RGI among WW and NWW. The primary data collection included offline and web-based questionnaire. A total of 1044 responses were considered for the analysis (545 WW and $499 \mathrm{NWW}$ ) using convenience sampling. The data was analyzed using ANOVA and linear regression. When age-wise cross-comparison was undertaken among WW and NWW, the results suggested: significant differences between 'mid-age' NWW and 'mid-age' WW and its susceptibility across all three RGIs viz. IRG, URG and VERG. A mid-aged-NWW when compared with young-WW showed similar behavior towards its susceptibility on IRG, URG and VERG. Additionally, 'elderly' NWW and 'mid-age' WW, indicated differences in their susceptibility towards VERG influences. Education-wise cross-comparison revealed: significant association between 'graduate' NWW and WW having education level 'PG\&above' towards IRG \& URG. A Graduate-NWW and a Postgraduate-WW suggested differences towards IRG and URG. Additionally, no significant difference was observed between NWW having education 'PG\&above' and WW having education 'below 12'. Cross-comparison of 'HI' among WW and NWW w.r.t their susceptibility towards RGI indicated that NWW and WW in the 'Low' HI level, didn't showcase significant differences towards IRG, URG and VERG. NWW in the household income level of 'Medium' and WW who are in the HI level of 'Low' portrayed significant differences across IRG influences. NWW in the 'Medium' HI level and WW in the 'Medium' HI level indicated significant differences towards the three RGIs. The differences suggested that special marketing efforts may be needed to reach the two groups (WW \& NWW) or the three socio-demographic levels as they could be considered as a part of the organizations target market. The paper concludes by discussing the social implications and the contribution of the study for academicians and marketers.
\end{abstract}

Keywords: Age, Demographic analysis, Education, Household income, Reference group influence, Women buying behavior. 


\section{Introduction}

Social Reference Group influence under the social and consumer psychology literature refers to conforming to group pressure which impacts consumers' product purchases (Lessig \& Park, 1978; Batra et.al., 2001). Due to the diversity exhibited by consumers' in their attitude and behavior, it has become difficult for market researchers to understand the influence of reference groups (RG) on buying decisions. By analysing these influences, marketers gauge consumers' individual lifestyle and self-concept which leads to creating social pressures ultimately affecting product purchases. The school of thought that exist with regards to reference group influence (RGI) consist of three forms including informational, utilitarian and value-expressive (Bearden and Etzel, 1982; Terry and Rao, 1992; Lessig and Park, 1978, 1977). Informational RG (IRG) is when a consumer vigorously searches for information from the groups who have appropriate expertise. The source of information is assumed to be the most credible in his surroundings (Kelman, 1961). An individual uses IRG by either searching for information actively or observing and making inferences (Lessig \& Park, 1977). Utilitarian RG (URG) is based on the conformity concept in which an individual conforms to the expectations/norms of the society (Asch, 1953). This is similar to 'compliance process' wherein an individual satisfies the groups' expectations by complying either to gain rewards or avoid punishment (Kelman, 1961). While, Value-Expressive RG (VERG) is based on 'Identification process' where an individual's motivation to support his self-concept or enhance his self-image is by associating himself with positive references or dissociating with negative references (Kelman, 1961). The studies on RGI has been researched by scholars across varied product and service categories (Xihao \& Yang, 2007; Terry and Hogg, 1996; Mehta et.al. 2001), consumer segments (Mehta et. al. 2001, Burnkrant \& Cousineau, 1975; Lessig \& Park, 1977) and cultures (Chiang \& Yu, 2010; Rajagopal, 2011). Studies on RGI varies from men to women where gender is an influential constituent in consumer buying behavior (Schiffman and Kanuk, 2007). It was witnessed that women were highly susceptible to RGI as compared to men and gender does make a difference in the overall consumer attitude towards product purchases (Vidyarthi, 2014; Nair \& Pillai, 2007; Holmberg \& Ohnfeldt, 2010). The current focus of the study is on women segment. Women no longer can be considered as a single segment (Bartos, 1977). Studies have shown that Working Women (WW) and Non-Working Women (NWW) differ in their buying pattern as they are susceptible to RG due to varying degrees of importance given to RG (Bartos, 1977; Fernandes \& Londhe, 2015). Socio-demographic variables like age, education, income etc. act as a representation to the socio-economic environment which an individual is raised with, which indirectly reflects on his/her buying habits (Shukla, 2008, Zanoli et.al., 2002). Despite researchers having worked on the topic of RGI on consumer behavior, there are no studies that have compared Working Women (WW) and Non-Working Women (NWW) in the research area involving RGI especially in the Indian context. The objective of the research is to probe into socio-demographic variables like age, education and household income and its impact on the susceptibility towards RGI among WW and NWW. 


\section{Literature Review}

\section{Role of RG on consumer segments}

An individual's attitude and behavior changes have been identified by the influence of RGs (Mehta, Lalwani \& Ping, 2001). This influence of RGs innately varies across different consumer segments and across different cultures (Terry \& Rao, 1992). Across WW and NWW, susceptibility to RG influence showed that NWW were influenced by husbands through IRG and confirmed with family through URG while WW were influenced by IRG by observing how others use the product (Fernandes \& Londhe, 2015). However, when students and NWW were studied, NWW showed lower susceptibility than students to group influences for a variety of products (Lessig \& Park, 1977). RG influence has played a significant role amongst WW where similar influence pattern was witnessed across various services in Singapore (Mehta et. al. 2001). Research also puts forth that females were more socially connected with the society and were psychologically more involved in shopping than males (Arnold \& Fisher, 1994; Gabriel \& Gardner, 1999; Maccoby, 1990).

Further-on, studies depicted that there is a significant difference between the role of social influence in consumer behavior and its relationship with other variables like age and gender differences (Josza, 2007).

\section{Role of Socio-Demographic Variables}

Buying behavior towards conspicuousness of the product becomes significant across certain demographic variables like age, gender, income or education (Shukla, 2008). However, when studied specific to women, literature review suggests that the influence of RG varies as per age (Kokoi, 2011) and working status of women (Fernandes and Londhe, 2014, 2015). Nationality and age have been the factors that have been identified as important by research scholars in the context of RGI (Xihao and Yang, 2007; Khan \& Khan, 2008). Studies suggested that in developing nations, age of the women and her family structure were responsible for her decisions in the family where-by older women who live in nuclear households were more liable towards family decision-making (Acharya et.al, 2010). Studies have also indicated that younger women were more susceptible to RGI as compared to older women (Kokoi, 2011). Age was also pertinent in cases where-in traditional values of collectivism-individualism reported negative relationship as age advances. i.e. it was expected that the youth were more individualistic in nature as compared to older age consumers (Brokaw \& Lakshman, 1995). Need differences also exist due to the differences in the distribution of age which results in difference in the amount of learning and knowledge attained by the consumers, familiarity with the product exists and the capacity of handling risks also increases. Studies on age have further indicated that although socialization is lifelong process, the learnings and knowledge gained are stronger at a younger age than when one grows old (Lessig \& Park, 1977).

Literature states that both employment and education have been empowering women over the years which has brought a positive impact in household decision making thereby reducing the inequalities in gender differences (Acharya et.al. 2010). This is true because women have become knowledgeable due to the effects of education, employment and their active participation in social mores (Martinez \& Polo, 1999). Studies have indicated that higher the education levels, higher is the capacity to think rationally and logically and hence would be 
influential in providing the source of product information from their knowledge attained (Zanoli et.al., 2002). Thus, based on the educational levels of a person, their buying behavior may vary (Wijesundera and Abeysekera, 2010).

The literature review contains research studies that justifies that demographic variables are important. Nonetheless, in published research, there is lack of attention on demographic variables w.r.t its susceptibility to RGI.

\section{Research Question and Gap}

Although there is some research on demographic variables, none of the studies investigated the susceptibility of RGI impacting consumer behavior. Additionally, none of the studies have sampled WW and NWW across different levels of age, education and household income (HI). This sample was selected for several reasons: differences among WW and NWW may arise due to the frequency of formal and informal groups they might be associating themselves with, peer pressures and the existence of social approval from the groups they associate with. The presumption is that substantial differences may be visible among the WW. The two segments may show differences due to the frequent informal social gatherings which they might be engaged in resulting in obtaining more information and social aids as a part of the social conformity.

The research would hence try to address the following research questions:

- How demographic variables like 'Age' levels affect the susceptibility of RGI among WW and NWW?

- How demographic variables like 'Educational' levels affect the susceptibility of RGI among WW and NWW?

- How demographic variables like 'Household income' levels affect the susceptibility of RGI among WW and NWW?

\section{Research Objective}

To understand the significant differences that exist among the various levels of age, education and household income with respect to their susceptibility to IRG, URG and VERG influences on WW and NWW.

\section{Hypothesis Development}

Taking cues from literature review, the following hypothesis are empirically tested in the study:

\section{Hypothesis 1}

H 1: Significant differences exist among the 'Age' levels with respect to their susceptibility to IRG, URG and VERG influences on WW and NWW. 


\section{Hypothesis 2}

H 2: Significant differences exist among 'Educational' levels with respect to their susceptibility to IRG, URG and VERG influences on WW and NWW.

\section{Hypothesis 3}

H 3: Significant differences exist among 'Household income' levels with respect to their susceptibility to IRG, URG and VERG influences on WW and NWW.

\section{Hypothesis 4}

H 4: Influence of IRG, URG and VERG changes within WW and within NWW based on the demographic variables.

\section{Method}

The primary data collection included offline and web-based questionnaire study using the tool survey monkey. As literature doesn't mention the confounding variables affecting purchase decision, the same could not be identified to be included in the study. Hence to minimize the effect of confounding variables, a very large sample size of $1105 \# \mathrm{WW}$ and NWW were distributed across Bangalore region covering various locations out of which only 1044 involving $545(52.2 \%) \mathrm{WW}$ and $499(47.8 \%) \mathrm{NWW}$ are considered in the final analysis. The participants were selected based on convenience sampling covering a larger consumer base. The sample of the study consisted of WW and NWW across age levels of <30 years, 30-50 years and > 50 years; Educational levels of '12\&below', 'Graduate', 'PG\&above'; and monthly household income levels of $<25 \mathrm{~K}, 25 \mathrm{~K}-50 \mathrm{~K}, 50 \mathrm{~K}-1 \mathrm{LAC} \&>1 \mathrm{LAC}$. The analysis of demographic variable data aided in discerning the characteristics of the respondents' susceptibility to RGI. In the online data collection, participants were invited by email to be a part of the survey and asked to fill and complete the survey. Data was also collected through shopper intercept interviews at various shopping malls and at residential institutions and the same were transcribed directly into the excel file. Statistical package SPSS was used to analyze the first three objectives of the study using ANOVA (Analysis of Variance) to examine the interaction effects. For analyzing the forth hypothesis, Linear Regression analysis was conducted to check the differential impact of RG influence within the individual segments of WW and NWW. The questionnaire involved RGI scale including 14 manifestation statements which was developed by Lessig \& Park (1977). The questionnaire has two parts. The first section (Part A) involves RGI scale including 14 manifestation statements. The second part (Part B) of the questionnaire included the demographic profiling of the respondents where information pertaining to income, age, education, occupation was captured. To adequately capture the concepts in the present setting which is the women segment, two items on IRG namely "I will buy only if my husband approves it" and "I gather information from online reviews/websites before making purchases" were included in the study based on the notion of online behavior gaining prominence. These items were the result of deliberations from 2 focus group discussions (FGD) which were conducted on WW and 2 FGDs being conducted on NWW. The responses were recorded through 5 point Likert scale ranging from 5=Strongly Agree, 4= Agree, 3= Neutral, 2= Disagree, 1= Strongly Disagree. 


\section{Analysis of Data}

Cross Comparison of 'Age' levels, 'Education' levels and 'Household Income (HI)' levels and their susceptibility towards RGIs across WW and NWW when combined in the ANOVA analysis are presented below:

H 1: Socio-Demographic Characteristics: Analysis of 'Age' levels among $W W$ and $N W W$ :

The evidence presented in Table 1, suggests that differences exist between WW and NWW across the three age levels viz. young ( $<30$ years), mid-age (30-50 years) and elderly ( $>50$ years) w.r.t its susceptibility towards RGIs.

Significant differences were found between 'young' WW $(\mathrm{p}=0.034)$ and 'young' NWW towards IRG. There was no URG and VERG differences among the two groups where equal importance is provided to URG and VERG type of influences. We found significant differences between 'mid-age' WW and 'mid-age' NWW and its susceptibility across all three RGIs viz. IRG, URG and VERG. Similarly, findings provide evidence that 'mid-age' WW and 'elderly' NWW depicted significant differences across all forms of RGIs. Findings provide evidence that 'elderly' WW and 'elderly' NWW showed differences towards IRG and URG influences. VERG showed no significant differences across age groups among WW and NWW except in the case when 'elderly' WW were compared with 'young' NWW who depicted differences in its susceptible towards VERG. Similarly, among 'Mid-age' WW and 'mid-age' NWW, differences were observed towards VERG. Additionally, 'mid-age' WW and 'elderly' NWW, indicated differences in their susceptibility towards VERG influences. It was seen that young WW and elderly WW resp. when compared with mid-age NWW showed similar behavior (no significant differences) towards its susceptibility on IRG, URG and VERG.

Table 1: Cross Comparison of Age

\begin{tabular}{|l|l|l|l|}
\hline WW & NWW & Non-Significant Difference in & Significant Differences in \\
\hline Young & Young & URG $(0.090)$, VERG $(0.577)$ & IRG $\left(0.034^{*}\right)$ \\
\hline Mid-age & Mid-age & - & $\begin{array}{l}\text { IRG }\left(0.015^{*}\right), \text { URG }\left(0.000^{*}\right), \\
\text { VERG }\left(0.025^{*}\right)\end{array}$ \\
\hline Elders & Elders & VERG $(0.121)$ & IRG $\left(0.001^{*}\right)$, URG $\left(0.034^{*}\right)$ \\
\hline Mid-age & Young & VERG $(0.318)$ & IRG $\left(0.002^{*}\right)$, URG $\left(0.003^{*}\right)$ \\
\hline Elders & Young & URG $(0.121)$ & IRG $\left(0.028^{*}\right)$, VERG $\left(0.035^{*}\right)$ \\
\hline Young & Mid-age & $\begin{array}{l}\text { IRG }(0.243), \quad \text { URG }(0.087), \\
\text { VERG }(0.986)\end{array}$ & - \\
\hline Elder & Mid-age & $\begin{array}{l}\text { IRG }(0.170), \text { URG }(0.174), \\
\text { VERG }(0.053)\end{array}$ & - \\
\hline Young & Elder & VERG $(0.765)$ & IRG $\left(0.000^{*}\right)$, URG $\left(0.010^{*}\right)$ \\
\hline Mid-age & Elder & & $\begin{array}{l}\text { IRG }\left(0.000^{*}\right), \text { URG }\left(0.000^{*}\right), \\
\text { VERG }\left(0.036^{*}\right)\end{array}$ \\
\hline
\end{tabular}


Further examination of WW and NWW susceptibility towards the three RGIs in their purchasing behavior w.r.t Age, a comparison of the mean scores was analysed as presented in Table 2:

Table 2: Results on Age difference for the three RGI/s among WW and NWW

WW

\begin{tabular}{|l|l|l|l|l|}
\hline RGI & $\begin{array}{l}\text { Demographic } \\
\text { variable: } \\
\text { Age }\end{array}$ & $\mathbf{N}$ & Mean Score & SD \\
\hline $\boldsymbol{I R G}$ & Young & 187 & 3.453 & 0.52514 \\
\hline & Mid_Aged & 294 & 3.5028 & 0.51394 \\
\hline & Elders & 64 & 3.5013 & 0.54306 \\
\hline & & & & \\
\hline $\boldsymbol{U R G}$ & Young & 187 & 3.1497 & 0.50245 \\
\hline & Mid_Aged & 294 & 3.2251 & 0.50571 \\
\hline & Elders & 64 & 3.167 & 0.48973 \\
\hline & & & & \\
\hline $\boldsymbol{V E R} \boldsymbol{G}$ & Young & 187 & 2.5297 & 0.59538 \\
\hline & Mid_Aged & 294 & 2.6543 & 0.63588 \\
\hline & Elders & 64 & 2.3516 & 0.57255 \\
\hline
\end{tabular}

\section{NWW}

\begin{tabular}{|c|c|c|c|c|}
\hline RGI & $\begin{array}{l}\text { Demographic } \\
\text { variable: } \\
\text { Age } \\
\end{array}$ & $\mathbf{N}$ & Mean Score & SD \\
\hline \multirow[t]{3}{*}{ IRG } & Young & 187 & 3.453 & 0.52514 \\
\hline & Mid_Aged & 294 & 3.5028 & 0.51394 \\
\hline & Elders & 64 & 3.5013 & 0.54306 \\
\hline \multirow[t]{3}{*}{$U R G$} & Young & 187 & 3.1497 & 0.50245 \\
\hline & Mid_Aged & 294 & 3.2251 & 0.50571 \\
\hline & Elders & 64 & 3.167 & 0.48973 \\
\hline \multirow[t]{3}{*}{ VERG } & Young & 187 & 2.5297 & 0.59538 \\
\hline & Mid_Aged & 294 & 2.6543 & 0.63588 \\
\hline & Elders & 64 & 2.3516 & 0.57255 \\
\hline
\end{tabular}

As persons move in their life cycle from middle to elderly stage, they tend to be free from work and family responsibilities. This reduction in formal roles in society and freedom from regular routine need not result in social isolation and reduction in the role of social RGI (Atchley, 1980). This was seen when comparing the differences among the two segments WW and NWW and its relationship with 'age'. The mean influence score of the WW young consumers is significantly higher than their NWW young counterpart (3.453 vs. 3.3091) for IRG, for URG the mean influence score of the WW young consumers is slightly higher than their NWW young counterpart (3.1497 vs. 3.0385) and for VERG - the mean score of the WW young and NWW 
young consumer groups was lesser in comparison to the value of 3 (with the mean test value of 3 on a total of 5 which is considered as a strong influence).

For the mid-age group, it is seen that the mean influence score of the WW Mid-age consumers is significantly higher than their NWW Mid-age counterpart (3.5028 vs. 3.3913) for IRG, for URG - the mean influence score of the WW Mid-age consumers is slightly higher than their NWW Mid-age counterpart (3.2251 vs. 3.0629) and for VERG - the mean score of the WW Mid-age and NWW Mid-age consumer groups was lesser in comparison to the value of 3 (with the mean test value of 3 on a total of 5 which is considered as a strong influence).

Similar results were observed across the WW \& NWW with respect to the 'elders' age groups.

The results could also be explained by the general perception that WW consumers (across all age groups) has a higher motivation to agree with the direct expression of IRG and URG statements than NWW consumers considering the mean scores although towards URG influence the two segments behaved similarly. Higher levels of social interactions by the elderly (IRG/URG) may be due to their past lifestyle and past work patterns and hence are susceptible to RGI (Palmore, 1968). However, in case of VERG influence the two segments showed differences on age factor although the mean scores were less than 3 indicating lesser motivation to agree.

H 2: Socio-Demographic Characteristics: Analysis of 'Education' levels among $W W$ and NWW:

The evidence presented in Table 3, offers social investigation onto the variations that exist between WW and NWW across the three educational levels viz. below 12, Graduate and PG\&above w.r.t its susceptibility towards RGIs.

Education levels across WW and NWW is significantly associated with the outcome measure i.e. RGI. Interestingly, WW who is highly educated (PG\&above) shows significant differences across all 3 forms of RGIs when compared with NWW who is less educated (below 12). The association between WW who has below 12 educational level when compared with NWW who has below 12 education yields a non-significant result ( $\mathrm{p}>0.05$ ) towards IRG and VERG. However, it is significant with URG. It is clear that women's education plays a significant role w.r.t its susceptibility to RGIs. Similarly, association between 'graduate' WW when compared with 'graduate' NWW yields a non-significant result $(\mathrm{p}>0.05)$ towards URG and VERG. However, it is significant with IRG. Further on, the association between WW having education level 'PG\&above' when compared with a 'graduate' NWW yields a significant result $(\mathrm{p}<0.05)$ towards IRG \& URG. Additionally, no significant difference was observed between WW having education 'below 12' and NWW having education 'PG\&above'. These differences and similarity may be because education impart feelings of self-worth and self-confidence, which are more important features for behavior and social change. 
Table 3: Cross Comparison of Education

\begin{tabular}{|l|l|l|l|}
\hline WW & NWW & Non-Significant Difference in & Significant Differences in \\
\hline Below 12 & Below 12 & IRG $(0.135)$, VERG $(0.458)$ & URG $\left(0.002^{*}\right)$ \\
\hline Graduate & Graduate & URG $(0.106)$, VERG $(0.149)$ & IRG $\left(0.001^{*}\right)$ \\
\hline PG\&above & PG\&above & IRG $(0.095)$, VERG $(0.159)$ & URG $\left(0.006^{*}\right)$ \\
\hline Graduate & Below 12 & VERG $(0.134)$ & IRG $\left(0.000^{*}\right)$, URG $\left(0.001^{*}\right)$ \\
\hline PG\&above & Below 12 & - & $\begin{array}{l}\text { IRG }\left(0.000^{*}\right), \text { URG }\left(0.000^{*}\right), \\
\text { VERG }\left(0.002^{*}\right)\end{array}$ \\
\hline Below 12 & Graduate & $\begin{array}{l}\text { IRG }(0.398), \text { URG }(0.072), \\
\text { VERG }(0.272)\end{array}$ & - \\
\hline PG\&above & Graduate & VERG $(0.737)$ & IRG $\left(0.001^{*}\right)$, URG $\left(0.004^{*}\right)$ \\
\hline Below 12 & PG\&above & $\begin{array}{l}\text { IRG }(0.964), \text { URG }(0.066), \\
\text { VERG }(0.807)\end{array}$ & - \\
\hline Graduate & PG\&above & URG $(0.114)$, VERG $(0.992)$ & IRG $\left(0.050^{*}\right)$ \\
\hline
\end{tabular}

Further examination of WW and NWW susceptibility towards the three RGIs in their purchasing behavior w.r.t Education, a comparison of the mean scores was analysed as presented in Table 4:

Table 4: Results on education difference for the three RGI/s among WW and NWW WW

\begin{tabular}{|c|c|c|c|c|}
\hline RGI & $\begin{array}{l}\text { Demographic } \\
\text { variable: } \\
\text { Education } \\
\end{array}$ & $\mathbf{N}$ & Mean Score & SD \\
\hline \multirow[t]{3}{*}{ IRG } & 12\&below & 39 & 3.4017 & 0.47886 \\
\hline & Grad & 156 & 3.5216 & 0.56811 \\
\hline & PG\&above & 350 & 3.4788 & 0.50309 \\
\hline \multirow[t]{3}{*}{$U R G$} & 12\&below & 39 & 3.2452 & 0.48717 \\
\hline & Grad & 156 & 3.1571 & 0.4749 \\
\hline & PG\&above & 350 & 3.2023 & 0.51727 \\
\hline \multirow[t]{3}{*}{ VERG } & 12\&below & 39 & 2.4968 & 0.53206 \\
\hline & Grad & 156 & 2.5236 & 0.62461 \\
\hline & PG\&above & 350 & 2.6082 & 0.62933 \\
\hline
\end{tabular}




\section{NWW}

\begin{tabular}{|l|l|l|l|l|}
\hline RGI & $\begin{array}{l}\text { Demographic } \\
\text { variable: } \\
\text { Education }\end{array}$ & $\mathbf{N}$ & Mean Score & SD \\
\hline IRG & $12 \&$ below & 137 & 3.2579 & 0.53404 \\
\hline & Grad & 191 & 3.3133 & 0.60575 \\
\hline & PG\&above & 171 & 3.396 & 0.58573 \\
\hline & & & & \\
\hline $\boldsymbol{U R G}$ & $12 \&$ below & 137 & 2.9827 & 0.44991 \\
\hline & Grad & 191 & 3.0625 & 0.58882 \\
\hline & PG\&above & 171 & 3.0662 & 0.55616 \\
\hline & & & & \\
\hline $\boldsymbol{V E R} \boldsymbol{G}$ & $12 \& b e l o w$ & 137 & 2.4097 & 0.66442 \\
\hline & Grad & 191 & 2.6283 & 0.70867 \\
\hline & PG\&above & 171 & 2.5238 & 0.66435 \\
\hline
\end{tabular}

When comparing the differences among the two segment WW and NWW, in terms of education; it is seen that the mean influence score of the WW having education level ' 12 \&below' is significantly higher than their NWW counterpart (3.4017 vs. 3.2579) for IRG influence, for URG influence - the mean influence score of the WW having education level ' 12 \&below' is also higher than their NWW counterpart (3.2452 vs. 2.9827) and for VERG influence - the mean score of the WW and NWW consumer groups was lesser in comparison to the value of 3 (with the mean test value of 3 on a total of 5 which is considered as a strong influence).

For the Graduate group, in case of IRG, it is seen that the mean influence score of the WWGraduate consumers is significantly higher than their NWW - Graduate counterpart (3.5216 vs. 3.3133). In case of URG, the mean influence score of the WW - Graduate consumers is slightly higher than their NWW - Graduate counterpart (3.1571 vs. 3.0625). In case of VERG, the mean score of the WW - Graduate and NWW -Graduate consumer groups were lesser in comparison to the value of 3 (with the mean test value of 3 on a total of 5 which is considered as a strong influence). Similar results were observed across the WW \& NWW with respect to the 'PG\&above' education group.

The results could also be explained by the general perception that WW consumers (across all education groups) has a higher motivation to agree with the direct expression of informational and to a certain aspect utilitarian statements than NWW consumers considering the mean scores while in case of VERG influence the two segments showed differences on education factor although the mean scores were less than 3 indicating lesser motivation to agree.

H 3: Socio-Demographic Characteristics: Analysis of Household Income levels `among WW and $N W W$ :

The evidence presented in Table 5, provides social investigation onto the variations that exist between WW and NWW across the three household income levels viz. Low $(\mathrm{HI}<50,000$, Medium (HI < 1Lakh) and High (HI> 1 Lakh) w.r.t its susceptibility towards RGIs.

Household income across WW and NWW is significantly associated with the outcome measure i.e. RGI. The WW and NWW belonging to the Medium HI levels, showed significant 
differences across all the three RGIs. WW who are in the HI level of 'Low' and NWW in the household income level of 'Medium' portrayed significant differences across IRG influences. Similarly, WW who are in the HI level of 'Low' and NWW in the household income level of 'High' portrayed significant differences across IRG influences. Additionally, WW in the Medium HI level suggested significant differences when compared with NWW who were in High HI level across IRG and URG. WW in the 'Medium' HI level and NWW in the 'Low' HI level suggested similar behavior towards RGI. Furthermore, WW and NWW in the 'Low' HI level, didn't showcase significant differences towards IRG, URG and VERG.

Table 5: Cross Comparison of Household Income (HI)

\begin{tabular}{|l|l|l|l|}
\hline WW & NWW & Non-Significant Difference in & Significant Differences in \\
\hline Low & Low & $\begin{array}{l}\text { IRG }(0.581), \text { URG }(0.877), \\
\text { VERG }(0.626)\end{array}$ & - \\
\hline Medium & Medium & - & $\begin{array}{l}\text { IRG }\left(0.004^{*}\right), \text { URG }\left(0.000^{*}\right), \\
\text { VERG }\left(0.028^{*}\right)\end{array}$ \\
\hline High & High & $\begin{array}{l}\text { IRG (0.194), URG (0.323), } \\
\text { VERG }(0.959)\end{array}$ & - \\
\hline Medium & Low & $\begin{array}{l}\text { IRG (0.090), URG (0.133), } \\
\text { VERG }(0.246)\end{array}$ & - \\
\hline High & Low & $\begin{array}{l}\text { IRG }(0.158), \text { URG }(0.771), \\
\text { VERG }(0.353)\end{array}$ & - \\
\hline Low & Medium & URG $(0.058)$, VERG $(0.645)$ & IRG $\left(0.007^{*}\right)$ \\
\hline High & Medium & $\begin{array}{l}\text { IRG (0.671), URG (0.226), } \\
\text { VERG }(0.260)\end{array}$ & - \\
\hline Low & High & URG $(0.223)$, VERG $(0.391)$ & IRG $\left(0.015^{*}\right)$ \\
\hline Medium & High & VERG $(0.960)$ & IRG $\left(0.007^{*}\right)$, URG $\left(0.032^{*}\right)$ \\
\hline
\end{tabular}

Further examination of WW and NWW susceptibility towards the three RGIs in their purchasing behavior w.r.t Household Income, a comparison of the mean scores was analysed as presented in Table 6:

Table 6: Results on Household Income difference for the three RGI/s among WW and NWW

WW

\begin{tabular}{|l|l|l|l|l|}
\hline RGI & $\begin{array}{l}\text { Demographic variable: } \\
\text { Household Income }\end{array}$ & $\mathbf{N}$ & Mean Score & SD \\
\hline $\boldsymbol{I R G}$ & $<25 \mathrm{~K}$ & 14 & 3.5476 & 0.23844 \\
\hline & $25 \mathrm{~K}-50 \mathrm{~K}$ & 244 & 3.4674 & 0.52211 \\
\hline & $50 \mathrm{~K}-1 \mathrm{LAC}$ & 216 & 3.5085 & 0.52196 \\
\hline & $>1 \mathrm{LAC}$ & 71 & 3.4660 & 0.55721 \\
\hline & & & & \\
\hline $\boldsymbol{U} \boldsymbol{R} \boldsymbol{}$ & $<25 \mathrm{~K}$ & 14 & 3.3795 & 0.5506 \\
\hline & $25 \mathrm{~K}-50 \mathrm{~K}$ & 244 & 3.1232 & 0.50146 \\
\hline & $50 \mathrm{~K}-1 \mathrm{LAC}$ & 216 & 3.2636 & 0.48661 \\
\hline & $>1 \mathrm{LAC}$ & 71 & 3.1769 & 0.52056 \\
\hline
\end{tabular}




\begin{tabular}{|l|l|l|l|l|}
\hline & & & & \\
\hline $\boldsymbol{V} \boldsymbol{R} \boldsymbol{G}$ & $<25 \mathrm{~K}$ & 14 & 2.6295 & 0.56727 \\
\hline & $25 \mathrm{~K}-50 \mathrm{~K}$ & 244 & 2.5085 & 0.60634 \\
\hline & 50K-1LAC & 216 & 2.6684 & 0.63837 \\
\hline & $>1 \mathrm{LAC}$ & 71 & 2.5167 & 0.61063 \\
\hline
\end{tabular}

NWW

\begin{tabular}{|l|l|l|l|l|}
\hline RGI & $\begin{array}{l}\text { Demographic variable: } \\
\text { Household Income }\end{array}$ & $\mathbf{N}$ & Mean Score & SD \\
\hline IRG & $<25 \mathrm{~K}$ & 6 & 3.0903 & 0.38498 \\
\hline & $25 \mathrm{~K}-50 \mathrm{~K}$ & 81 & 3.3915 & 0.63467 \\
\hline & $50 \mathrm{~K}-1 \mathrm{LAC}$ & 387 & 3.3349 & 0.56628 \\
\hline & $>1 \mathrm{LAC}$ & 25 & 3.0400 & 0.60661 \\
\hline & & & & \\
\hline $\boldsymbol{U} \boldsymbol{R} \boldsymbol{G}$ & $<25 \mathrm{~K}$ & 6 & 3.0000 & 0.29843 \\
\hline & $25 \mathrm{~K}-50 \mathrm{~K}$ & 81 & 3.0918 & 0.5259 \\
\hline & $50 \mathrm{~K}-1 \mathrm{LAC}$ & 387 & 3.0384 & 0.54681 \\
\hline & $>1 \mathrm{LAC}$ & 25 & 2.9425 & 0.58461 \\
\hline & & & & \\
\hline $\boldsymbol{V E} \boldsymbol{R} \boldsymbol{G}$ & $<25 \mathrm{~K}$ & 6 & 2.7604 & 0.60132 \\
\hline & $25 \mathrm{~K}-50 \mathrm{~K}$ & 81 & 2.5386 & 0.64322 \\
\hline & $50 \mathrm{~K}-1 \mathrm{LAC}$ & 387 & 2.5263 & 0.6958 \\
\hline & $>1 \mathrm{LAC}$ & 25 & 2.5525 & 0.71299 \\
\hline
\end{tabular}

Working women with household income levels $<25 \mathrm{~K}$ showed higher (mean values > 3.5) susceptibility towards IRG while NWW across all the income levels depicted (moderate 3 to high 3.5) susceptibility towards IRG. Additionally, NWW having household income >1LAC were the least susceptible (mean values < 3) to URG while NWW in other household income levels exhibited (moderate 3 to high 3.5) susceptibility towards URG. WW with household income $<25 \mathrm{~K}$ displayed greater levels of susceptibility as compared to other income levels towards URG. Subsequently, in case of VERG, although differences existed among household income and its susceptibility towards VERG on WW, the mean values for all income were lower (mean values < 3) and less than 3 indicates lesser motivation to agree and hence were suggested to be the least susceptible to VERG. NWW with household income $<25 \mathrm{~K}$ displayed comparatively higher levels of susceptibility (mean score 2.7604) towards VERG influences in comparison to other levels of household income. The results explained that the two segments showed differences on household income towards RGIs. 
H 4: Influence of IRG, URG and VERG changes within WW based on the demographic variables.

Table 7: Influence of IRG w.r.t 'Age' on WW

\begin{tabular}{|c|c|c|c|c|c|c|}
\hline \multicolumn{7}{|c|}{ Coefficients $^{\mathbf{a}}$} \\
\hline \multirow{2}{*}{\multicolumn{2}{|c|}{ Model }} & \multicolumn{2}{|c|}{ Unstandardized Coefficients } & \multirow{2}{*}{$\begin{array}{c}\text { Standardized } \\
\text { Coefficients } \\
\text { Beta }\end{array}$} & \multirow[b]{2}{*}{$\mathrm{t}$} & \multirow[b]{2}{*}{ Sig. } \\
\hline & & B & Std. Error & & & \\
\hline \multirow[t]{3}{*}{1} & (Constant) & 3.454 & .038 & & 90.556 & .000 \\
\hline & Mid_aged & .050 & .049 & .047 & 1.016 & .310 \\
\hline & Elders & .048 & .076 & .030 & .639 & .523 \\
\hline
\end{tabular}

Predictors: Constant (Young), Mid_aged, Elders

\section{Interpretation:}

The influence of IRG is not statistically significant for Mid_aged and Elders when compared to Young Working Women.

Table 8: Influence of URG w.r.t 'Age' on WW

\begin{tabular}{|c|c|c|c|c|c|c|}
\hline \multicolumn{7}{|c|}{ Coefficients $^{\mathbf{a}}$} \\
\hline \multirow{2}{*}{\multicolumn{2}{|c|}{ Model }} & \multicolumn{2}{|c|}{ Unstandardized Coefficients } & \multirow{2}{*}{$\begin{array}{c}\text { Standardized } \\
\text { Coefficients } \\
\text { Beta } \\
\end{array}$} & \multirow[b]{2}{*}{$\mathrm{t}$} & \multirow[b]{2}{*}{ Sig. } \\
\hline & & $\mathrm{B}$ & Std. Error & & & \\
\hline \multirow[t]{3}{*}{1} & (Constant) & 3.454 & .038 & & 90.556 & .000 \\
\hline & Mid_aged & .050 & .049 & .047 & 1.016 & .310 \\
\hline & Elders & .048 & .076 & .030 & .639 & .523 \\
\hline
\end{tabular}

a. Dependent Variable: IRG;

\section{Interpretation:}

The influence of URG is not statistically significant for Mid_aged and Elders when compared to Young Working Women.

Table 9: Influence of VERG w.r.t 'Age' on WW

\begin{tabular}{|c|c|c|c|c|c|c|}
\hline \multicolumn{7}{|c|}{ Coefficients $^{\mathbf{a}}$} \\
\hline \multirow{2}{*}{\multicolumn{2}{|c|}{ Model }} & \multicolumn{2}{|c|}{ Unstandardized Coefficients } & \multirow{2}{*}{$\begin{array}{c}\text { Standardized } \\
\text { Coefficients } \\
\text { Beta } \\
\end{array}$} & \multirow[b]{2}{*}{$\mathrm{t}$} & \multirow[b]{2}{*}{ Sig. } \\
\hline & & $\mathrm{B}$ & Std. Error & & & \\
\hline \multirow[t]{3}{*}{1} & (Constant) & 2.531 & .045 & & 56.254 & .000 \\
\hline & Mid_aged & .125 & .058 & .100 & 2.164 & .031 \\
\hline & Elders & -.178 & .089 & -.092 & -1.998 & .046 \\
\hline
\end{tabular}

a. Dependent Variable: VERG 


\section{Interpretation:}

- The influence of VERG is significantly higher for Mid_aged when compared to Young Working Women.

- The influence of VERG is significantly lower for Elders when compared to Young Working Women.

Table 10: Influence of IRG w.r.t 'Education' on WW

\begin{tabular}{|c|c|c|c|c|c|c|}
\hline \multicolumn{7}{|c|}{ Coefficients $^{\mathbf{a}}$} \\
\hline \multirow{2}{*}{\multicolumn{2}{|c|}{ Model }} & \multicolumn{2}{|c|}{ Unstandardized Coefficients } & \multirow{2}{*}{$\begin{array}{c}\text { Standardized } \\
\text { Coefficients } \\
\text { Beta } \\
\end{array}$} & \multirow[b]{2}{*}{$\mathrm{t}$} & \multirow[b]{2}{*}{ Sig. } \\
\hline & & $\mathrm{B}$ & Std. Error & & & \\
\hline \multirow[t]{3}{*}{1} & (Constant) & 3.480 & .028 & & 124.897 & .000 \\
\hline & $12^{\text {th }} \&$ below & -.078 & .088 & -.039 & -.891 & .373 \\
\hline & Grad & .043 & .050 & .037 & .856 & .392 \\
\hline
\end{tabular}

a. Dependent Variable: IRG

Predictors: Constant (PG\&Above), Grad, 12th \& below

\section{Interpretation:}

The influence of IRG is not statistically significant for education 12th\&below and Graduation compared to qualification PG\&Above among Working Women.

Table 11: Influence of URG w.r.t 'Education' on WW

\begin{tabular}{|c|c|c|c|c|c|c|}
\hline \multicolumn{7}{|c|}{ Coefficients $^{\mathrm{a}}$} \\
\hline \multirow{2}{*}{\multicolumn{2}{|c|}{ Model }} & \multicolumn{2}{|c|}{ Unstandardized Coefficients } & \multirow{2}{*}{$\begin{array}{c}\text { Standardized } \\
\text { Coefficients } \\
\text { Beta } \\
\end{array}$} & \multirow[b]{2}{*}{$\mathrm{t}$} & \multirow[b]{2}{*}{ Sig. } \\
\hline & & $\mathrm{B}$ & Std. Error & & & \\
\hline \multirow[t]{3}{*}{1} & (Constant) & 3.203 & .027 & & 119.046 & .000 \\
\hline & $12^{\text {th }} \&$ below & .043 & .085 & .022 & .503 & .615 \\
\hline & Grad & -.045 & .048 & -.040 & -.927 & .354 \\
\hline
\end{tabular}

a. Dependent Variable: URG

\section{Interpretation:}

The influence of URG is not statistically significant for education 12th\&below and Graduation compared to qualification PG\&Above among Working Women. 
Table 12: Influence of VERG w.r.t 'Education' on WW

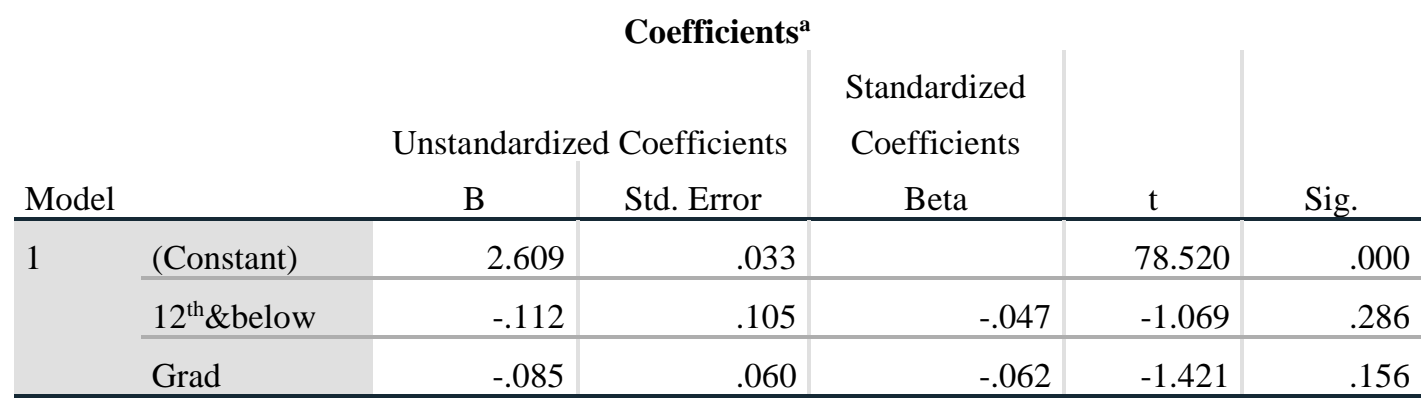

a. Dependent Variable: VERG

Interpretation: The influence of VERG is not statistically significant for education 12th\&below and Graduation compared to qualification PG\&Above among Working Women.

Table 13: Influence of IRG w.r.t 'Household_Income' on WW

\begin{tabular}{|c|c|c|c|c|c|c|}
\hline \multicolumn{7}{|c|}{ Coefficients $^{\mathbf{a}}$} \\
\hline \multirow{2}{*}{\multicolumn{2}{|c|}{ Model }} & \multicolumn{2}{|c|}{ Unstandardized Coefficients } & \multirow{2}{*}{$\begin{array}{c}\text { Standardized } \\
\text { Coefficients } \\
\text { Beta } \\
\end{array}$} & \multirow[b]{2}{*}{$\mathrm{t}$} & \multirow[b]{2}{*}{ Sig. } \\
\hline & & $\mathrm{B}$ & Std. Error & & & \\
\hline \multirow[t]{3}{*}{1} & (Constant) & 3.488 & .038 & & 92.089 & .000 \\
\hline & $50 \mathrm{~K} \_1 \mathrm{Lac}$ & .001 & .056 & .001 & .013 & .990 \\
\hline & $>1 \mathrm{Lac}$ & -.114 & .104 & -.061 & -1.100 & .272 \\
\hline
\end{tabular}

a. Dependent Variable: IRG

Predictors: Constant (<50K), 50K-1Lac, $>1 \mathrm{Lac}$

Interpretation: The influence of IRG is not statistically significant for $50 \mathrm{~K}$ to $1 \mathrm{Lac} \&>1 \mathrm{Lac}$ compared to $<50 \mathrm{~K}$ on WW.

Table 14: Influence of URG w.r.t 'Household_Income' on WW

\begin{tabular}{|c|c|c|c|c|c|c|}
\hline \multicolumn{7}{|c|}{ Coefficients $^{\mathbf{a}}$} \\
\hline \multirow{2}{*}{\multicolumn{2}{|c|}{ Model }} & \multicolumn{2}{|c|}{ Unstandardized Coefficients } & \multirow{2}{*}{$\begin{array}{c}\text { Standardized } \\
\text { Coefficients } \\
\text { Beta } \\
\end{array}$} & \multirow[b]{2}{*}{$\mathrm{t}$} & \multirow[b]{2}{*}{ Sig. } \\
\hline & & $\mathrm{B}$ & Std. Error & & & \\
\hline \multirow[t]{3}{*}{1} & (Constant) & 3.144 & .039 & & 81.310 & .000 \\
\hline & 50K_1Lac & .136 & .058 & .130 & 2.362 & .019 \\
\hline & $>11 \mathrm{ac}$ & .030 & .106 & .016 & .283 & .778 \\
\hline
\end{tabular}

a. Dependent Variable: URG 


\section{Interpretation:}

- The influence of URG is significantly higher for those in the income level of $50 \mathrm{~K}$ to $1 \mathrm{Lac}$ when compared to $<50 \mathrm{~K}$ on WW.

- The influence of URG is not statistically significant for those in the income level of $>1 \mathrm{Lac}$ when compared to $<50 \mathrm{~K}$ on WW.

Table 15: Influence of VERG w.r.t 'Household_Income' on WW

\begin{tabular}{|c|c|c|c|c|c|c|}
\hline \multicolumn{7}{|c|}{ Coefficients $^{\mathrm{a}}$} \\
\hline & & \multicolumn{2}{|c|}{ Unstandardized Coefficients } & \multirow{2}{*}{$\begin{array}{c}\text { Standardized } \\
\text { Coefficients } \\
\text { Beta }\end{array}$} & \multirow[b]{2}{*}{$\mathrm{t}$} & \multirow[b]{2}{*}{ Sig. } \\
\hline \multicolumn{2}{|c|}{ Model } & $\mathrm{B}$ & Std. Error & & & \\
\hline \multirow[t]{3}{*}{1} & (Constant) & 2.518 & .047 & & 53.651 & .000 \\
\hline & $50 \mathrm{~K} \_1 \mathrm{Lac}$ & .185 & .070 & .145 & 2.657 & .008 \\
\hline & $>1 \mathrm{Lac}$ & .187 & .129 & .079 & 1.449 & .148 \\
\hline
\end{tabular}

a. Dependent Variable: VERG

\section{Interpretation:}

- The influence of VERG is significantly higher for those in the income level of $50 \mathrm{~K}$ to $1 \mathrm{Lac}$ when compared to $<50 \mathrm{~K}$ on WW.

- The influence of VERG is not statistically significant for those in the income level of $>1 \mathrm{Lac}$ when compared to $<50 \mathrm{~K}$ on WW.

$H$ 4: Influence of IRG, URG and VERG changes within NWW based on the demographic variables.

Table 16: Influence of IRG w.r.t 'Age' on NWW

\begin{tabular}{|c|c|c|c|c|c|c|}
\hline \multicolumn{7}{|c|}{ Coefficients $^{\mathrm{a}}$} \\
\hline \multirow{2}{*}{\multicolumn{2}{|c|}{ Model }} & \multicolumn{2}{|c|}{ Unstandardized Coefficients } & \multirow{2}{*}{$\begin{array}{c}\text { Standardized } \\
\text { Coefficients } \\
\text { Beta } \\
\end{array}$} & \multirow[b]{2}{*}{$\mathrm{t}$} & \multirow[b]{2}{*}{ Sig. } \\
\hline & & $\mathrm{B}$ & Std. Error & & & \\
\hline \multirow[t]{3}{*}{1} & (Constant) & 3.310 & .062 & & 53.261 & .000 \\
\hline & Mid_aged & .082 & .071 & .070 & 1.163 & .245 \\
\hline & Elders & -.120 & .081 & -.090 & -1.486 & .138 \\
\hline
\end{tabular}

a. Dependent Variable: IRG

Predictors: Constant (Young), Mid_aged, Elders 
Interpretation: The influence of IRG is not statistically significant for Mid_aged and Elders compared to Young NWW.

Table 17: Influence of URG w.r.t 'Age' on NWW

\begin{tabular}{|c|c|c|c|c|c|c|}
\hline \multicolumn{7}{|c|}{ Coefficients $^{\mathrm{a}}$} \\
\hline \multirow{2}{*}{\multicolumn{2}{|c|}{ Model }} & \multicolumn{2}{|c|}{ Unstandardized Coefficients } & \multirow{2}{*}{$\begin{array}{c}\text { Standardized } \\
\text { Coefficients } \\
\text { Beta } \\
\end{array}$} & \multirow[b]{2}{*}{$\mathrm{t}$} & \multirow[b]{2}{*}{ Sig. } \\
\hline & & $\mathrm{B}$ & Std. Error & & & \\
\hline \multirow[t]{3}{*}{1} & (Constant) & 3.040 & .059 & & 51.892 & .000 \\
\hline & Mid_aged & .024 & .067 & .022 & .363 & .717 \\
\hline & Elders & -.043 & .076 & -.035 & -.571 & .568 \\
\hline
\end{tabular}

a. Dependent Variable: URG

Interpretation: The influence of URG is not statistically significant for Mid_aged and Elders compared to Young NWW.

Table 18: Influence of VERG w.r.t 'Age' on NWW

\begin{tabular}{|c|c|c|c|c|c|c|}
\hline \multicolumn{7}{|c|}{ Coefficients $^{\mathrm{a}}$} \\
\hline \multirow{2}{*}{\multicolumn{2}{|c|}{ Model }} & \multicolumn{2}{|c|}{ Unstandardized Coefficients } & \multirow{2}{*}{$\begin{array}{c}\text { Standardized } \\
\text { Coefficients } \\
\text { Beta }\end{array}$} & \multirow[b]{2}{*}{$\mathrm{t}$} & \multirow[b]{2}{*}{ Sig. } \\
\hline & & $\mathrm{B}$ & Std. Error & & & \\
\hline \multirow[t]{3}{*}{1} & (Constant) & 2.576 & .074 & & 34.778 & .000 \\
\hline & Mid_aged & -.044 & .084 & -.032 & -.525 & .600 \\
\hline & Elders & -.067 & .096 & -.043 & -.700 & .484 \\
\hline
\end{tabular}

a. Dependent Variable: VERG

Interpretation: The influence of VERG is not statistically significant for Mid_aged and Elders compared to Young NWW. 
Table 19: Influence of IRG w.r.t 'Education' on NWW

\begin{tabular}{|c|c|c|c|c|c|c|}
\hline \multicolumn{7}{|c|}{ Coefficients $^{\mathbf{a}}$} \\
\hline \multirow{2}{*}{\multicolumn{2}{|c|}{ Model }} & \multicolumn{2}{|c|}{ Unstandardized Coefficients } & \multirow{2}{*}{$\begin{array}{c}\text { Standardized } \\
\text { Coefficients } \\
\text { Beta }\end{array}$} & \multirow[b]{2}{*}{$\mathrm{t}$} & \multirow[b]{2}{*}{ Sig. } \\
\hline & & $\mathrm{B}$ & Std. Error & & & \\
\hline \multirow[t]{3}{*}{1} & (Constant) & 3.397 & .044 & & 76.589 & .000 \\
\hline & $12^{\text {th }} \&$ Below & -.138 & .066 & -.106 & -2.071 & .039 \\
\hline & Grad & -.083 & .061 & -.069 & -1.354 & .176 \\
\hline
\end{tabular}

a. Dependent Variable: IRG

Predictors: Constant (Pg\&Above), Grad, 12th \& below

\section{Interpretation:}

- The influence of IRG is significantly lower for those having educational qualification 12 th \& Below when compared to those who are PG\&Above on NWW.

- The influence of IRG is not statistically significant for graduates when compared to those who are PG\&Above on NWW.

Table 20: Influence of URG w.r.t 'Education' on NWW

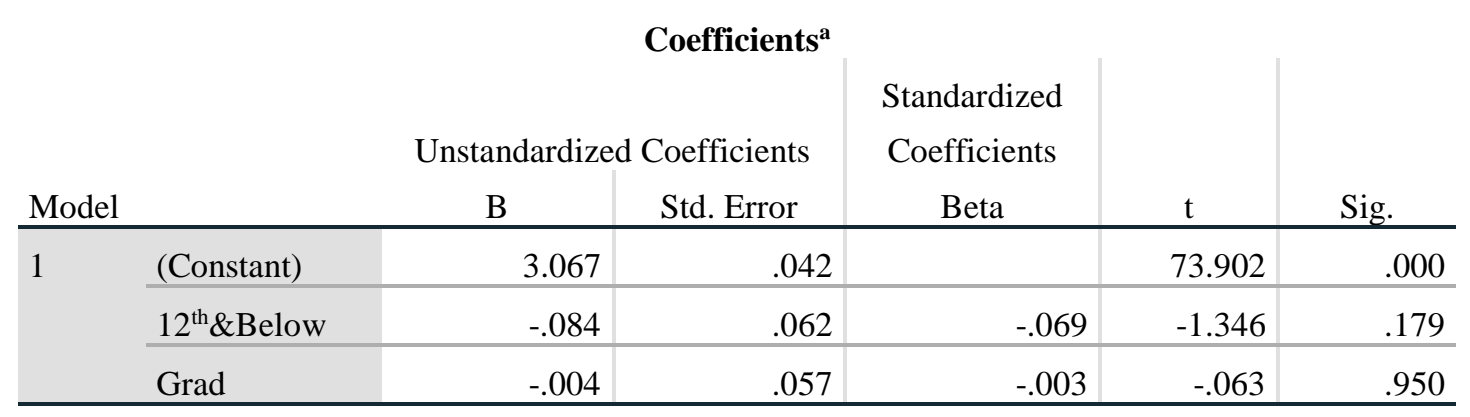

a. Dependent Variable: URG

Interpretation: The influence of URG is not statistically significant for those having educational qualification 12th\&Below and Graduates compared to PG\&Above on NWW. 
Table 21: Influence of VERG w.r.t 'Education' on NWW

\begin{tabular}{|c|c|c|c|c|c|c|}
\hline \multicolumn{7}{|c|}{ Coefficients $^{\mathrm{a}}$} \\
\hline \multirow{2}{*}{\multicolumn{2}{|c|}{ Model }} & \multicolumn{2}{|c|}{ Unstandardized Coefficients } & \multirow{2}{*}{$\begin{array}{c}\text { Standardized } \\
\text { Coefficients } \\
\text { Beta } \\
\end{array}$} & \multirow[b]{2}{*}{$\mathrm{t}$} & \multirow[b]{2}{*}{ Sig. } \\
\hline & & $\mathrm{B}$ & Std. Error & & & \\
\hline \multirow[t]{3}{*}{1} & (Constant) & 2.525 & .052 & & 48.443 & .000 \\
\hline & $12^{\text {th }} \&$ Below & -.114 & .078 & -.074 & -1.460 & .145 \\
\hline & Grad & .104 & .072 & .074 & 1.453 & .147 \\
\hline
\end{tabular}

a. Dependent Variable: VERG

Interpretation: The influence of VERG is not statistically significant for those having educational qualification 12th\&Below and Graduates compared to PG\&Above on NWW.

Table 22: Influence of IRG w.r.t 'Household_Income' on NWW

\begin{tabular}{|c|c|c|c|c|c|c|}
\hline \multicolumn{7}{|c|}{ Coefficients $^{\mathrm{a}}$} \\
\hline & & \multicolumn{2}{|c|}{ Unstandardized Coefficients } & \multirow{2}{*}{$\begin{array}{c}\text { Standardized } \\
\text { Coefficients } \\
\text { Beta } \\
\end{array}$} & \multirow[b]{2}{*}{$\mathrm{t}$} & \multirow[b]{2}{*}{ Sig. } \\
\hline \multicolumn{2}{|c|}{ Model } & $\mathrm{B}$ & Std. Error & & & \\
\hline \multirow[t]{3}{*}{1} & (Constant) & 3.445 & .079 & & 43.633 & .000 \\
\hline & $50 \mathrm{~K} \_1 \mathrm{Lac}$ & -.121 & .087 & -.086 & -1.394 & .164 \\
\hline & $>1 \mathrm{Lac}$ & -.335 & .171 & -.121 & -1.966 & .050 \\
\hline
\end{tabular}

a. Dependent Variable: IRG

Predictors: Constant (<50K), 50K-1Lac, $>1 \mathrm{Lac}$

\section{Interpretation:}

- The influence of IRG is not statistically significant for those in the income level of $50 \mathrm{~K}$ to $1 \mathrm{Lac}$ when compared to $<50 \mathrm{~K}$ on NWW.

- The influence of IRG is significantly lower for those in the income level of $>1 \mathrm{Lac}$ when compared to $<50 \mathrm{~K}$ on NWW. 
Table 23: Influence of URG w.r.t 'Household_Income' on NWW

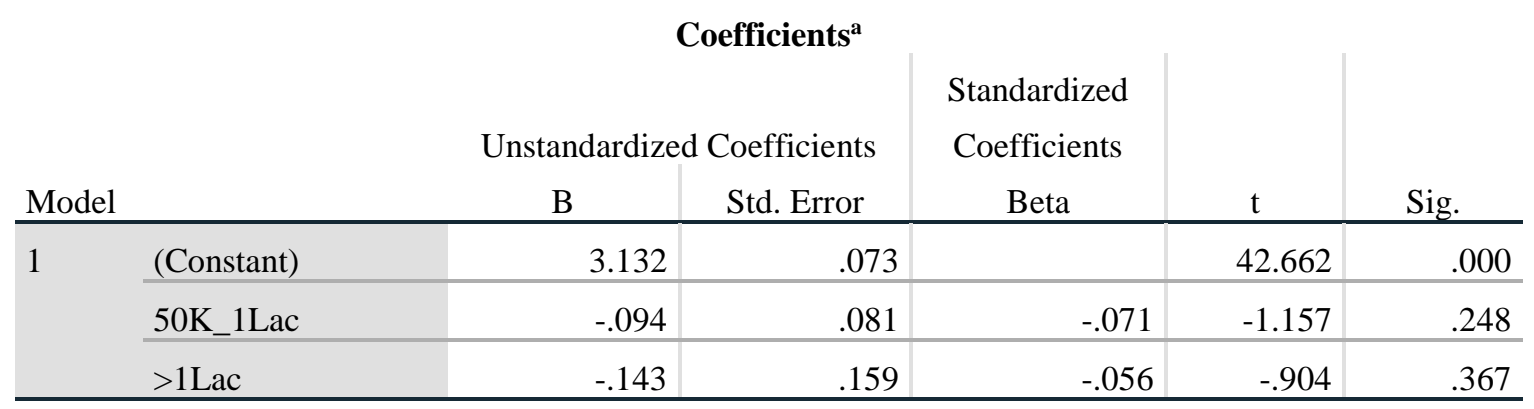

a. Dependent Variable: URG

Interpretation: The influence of URG is not statistically significant for those in the income level of $50 \mathrm{~K}$ to $1 \mathrm{Lac}$ and $>1 \mathrm{Lac}$ compared to $<50 \mathrm{~K}$ on NWW.

Table 24: Influence of VERG w.r.t 'Household_Income' on WW

\begin{tabular}{|c|c|c|c|c|c|c|}
\hline \multicolumn{7}{|c|}{ Coefficients $^{\mathrm{a}}$} \\
\hline \multirow{2}{*}{\multicolumn{2}{|c|}{ Model }} & \multicolumn{2}{|c|}{ Unstandardized Coefficients } & \multirow{2}{*}{$\begin{array}{c}\text { Standardized } \\
\text { Coefficients } \\
\text { Beta } \\
\end{array}$} & \multirow[b]{2}{*}{$\mathrm{t}$} & \multirow[b]{2}{*}{ Sig. } \\
\hline & & $\mathrm{B}$ & Std. Error & & & \\
\hline \multirow[t]{3}{*}{1} & (Constant) & 2.564 & .095 & & 26.991 & .000 \\
\hline & $50 \mathrm{~K} \_1 \mathrm{Lac}$ & -.020 & .105 & -.012 & -.194 & .846 \\
\hline & $>1 \mathrm{Lac}$ & .130 & .205 & .039 & 632 & .528 \\
\hline
\end{tabular}

a. Dependent Variable: VERG

Interpretation: The influence of VERG is not statistically significant for those in the income level of $50 \mathrm{~K}$ to $1 \mathrm{Lac}$ and $>1 \mathrm{Lac}$ compared to $<50 \mathrm{~K}$ on NWW.

\section{Summary of Findings}

The findings support the hypothesized relationships. This suggests that socio-demographic variables affected WW and NWW's susceptibility towards RGIs. The findings of the social interventions are:

'Age' and its susceptibility to RGI: Cross comparison of age levels among WW and NWW (Table 1) suggested that young NWW and young WW differ in their susceptibility towards IRG. The way a young woman searches for information have proved to be different and this may be obvious in case of WW as she is exposed to more sources of information like experts' opinion in comparison to NWW. Findings provide evidence that the 'elderly' NWW and 'elderly' WW showed differences towards IRG and URG influences. The 'mid age' NWW when compared with 'young' WW and 'elderly' WW resp. showed similar behavior towards its susceptibility 
on IRG, URG and VERG and hence marketers can consider them as a single segment. Young NWW and the elderly WW were susceptible (showed significant interaction effect) towards VERG and hence marketers could deal with them accordingly to boost their respective selfimage and self-concept. This confirmed our basic hypothesis $\mathrm{H} 1$ which indicated that differences exist among WW and NWW and their susceptibility towards RGI w.r.t 'Age' levels.

'Education' and its susceptibility to RGI: Educational levels have indicated susceptibility towards RGIs across NWW and WW (Table 3). Cross comparison of the educational levels revealed significant differences among WW and NWW towards RGIs. Significant differences were observed among NWW with education 'below 12' and WW with educational level 'PG\& above' towards IRG, URG and VERG influences. Additionally, a Graduate NWW and a post graduate WW suggested differences towards IRG and URG. Marketers should consider a graduate NWW and a graduate WW having educational level 'below 12' as a single segment as they show similarity in their susceptibility towards IRG, URG and VERG. Similarly, Marketers should consider NWW having qualification 12\&above and WW having educational level below 12 as a single segment as they show similarity in their susceptibility towards IRG, URG and VERG. These differences and similarity may be because education impart feelings of self-worth and self-confidence, which are more important features for behavior and social change. This confirmed our hypothesis $\mathrm{H} 2$ which indicated that differences exist among WW and NWW and their susceptibility towards RGI w.r.t 'Education' levels.

'Household Income (HI)' and its susceptibility to RGI: It was interesting to observe that in majority of the cross-comparison cases involving household income (HI) levels (Table 5), WW and NWW portrayed similar buying behavior w.r.t their susceptibility towards reference group influence. The study indicated that NWW and WW in the 'Low' HI level, didn't showcase significant differences towards IRG, URG and VERG. Similarly, NWW in the 'Low' HI level and a WW in the 'Medium' HI level suggested similar behavior towards RGIs. Furthermore, NWW in the 'Medium' HI level and WW in the 'Medium' HI level indicated significant differences towards the three RGIs. Thus, it was evident that household income levels had influence on the buying behavior. This comparison helped in examining and explaining the buying behavior w.r.t susceptibility towards RGI. It can be concluded that depending on the type of the cross-comparison w.r.t the levels of $\mathrm{HI}$, it constitutes an important market segmentation criterion for the marketers. This confirmed our third hypothesis H3. 
Within the individual segments, following are the inferences that can be drawn w.r.t the most susceptible demographic group across RGIs.

WW

\begin{tabular}{|l|l|l|}
\hline RGI & Demographic variable & $\begin{array}{l}\text { Most susceptible group (based on } \\
\text { mean score) }\end{array}$ \\
\hline IRG & Age & Mid_Aged (3.5028) \\
\hline & Education & Graduates $(3.5216)$ \\
\hline & Household_Income $(\mathrm{pm})$ & $<25 \mathrm{~K}(3.5476)$ \\
\hline & & \\
\hline URG & Age & Mid_Aged (3.2251) \\
\hline & Education & $12^{\text {th } \& \text { Below }(3.2452)}$ \\
\hline & Household_Income $(\mathrm{pm})$ & $<25 \mathrm{~K}(3.3795)$ \\
\hline VERG & & \\
\hline & Age & Mid_Aged $(2.6543)$ \\
\hline & Education & PG\&Above $(2.6082)$ \\
\hline & Household_Income $(\mathrm{pm})$ & 50K - 1Lac (2.6684) \\
\hline
\end{tabular}

\section{NWW}

\begin{tabular}{|l|l|l|}
\hline RGI & Demographic variable & $\begin{array}{l}\text { Most susceptible group (based on } \\
\text { mean score) }\end{array}$ \\
\hline IRG & Age & Mid_Aged (3.3913) \\
\hline & Education & PG\&Above (3.396) \\
\hline & Household_Income $(\mathrm{pm})$ & 25K - 50K (3.3915) \\
\hline & & \\
\hline URG & Age & Mid_Aged (3.0629) \\
\hline & Education & PG\&Above (3.0662) \\
\hline & Household_Income $(\mathrm{pm})$ & 25K - 50K (3.0918) \\
\hline VERG & Age & Young (2.5749) \\
\hline & Education & Graduate $(2.6283)$ \\
\hline & Household_Income $(\mathrm{pm})$ & $<25 \mathrm{~K}(2.7604)$ \\
\hline
\end{tabular}

This makes it clear that these three socio-demographic characteristics play a significant role in decision making which was inferred through an investigation carried out through ANOVA.

Thus H1, H2, H3 were supported indicating strong association of demographic variables on RGIs among WW and NWW.

Additionally, the differential impact of RGI within the individual segments of WW and NWW was proved using linear regression analysis (Table 7 to Table 24). This confirmed our hypothesis $\mathrm{H} 4$ which indicated that the influence of IRG, URG and VERG changes within WW \& NWW based on demographic variables. 


\section{Discussion}

The magnitude of scores did show that all age groups were susceptible to IRG (Table 2). They attached greater importance to IRG (as supported by Burnkrant \& Cousineau 1975) suggesting marketers' direct consumers' attention through symbols of product quality. Also, as indicated in literature, elderly WW and NWW resp. are no less susceptible to RGI at least on IRG and URG but are less susceptible in comparison to mid-aged and young women. A mid-age WW was more sensitive to the influence of others in the product selection process (as supported by Greco, 2015). Further-on, the data depicted elderly WW to be the least susceptible to VERG influence while mid-age WW were slightly more susceptible to VERG influence which implies that they maintain a better and an active lifestyle as compared to other age groups (as supported by Shukla, 2008; Greco, 2015). Thus, middle aged women are a lucrative target segment which is untapped by marketers (as supported by Spero \& Stone, 2004). This is logical as due to the experience of WW in industry, effect of celebrities or advertisements impacting decision would no longer be the impression while making a product choice. Being value expressive would matter for all NWW and hence their scores were slightly better than WW. However, based on the magnitude of the mean scores, the VERG scores depicted that psychological association was not relevant to any age groups for WW and NWW (as supported by Greco, 2015) and hence marketers may develop communication messages which simultaneously appeal to all the age groups among WW and NWW.

Examination of the variable 'education' revealed that education impacted WW and NWW influence on RG while making product decisions. Cross comparison of education levels (Table 3) provided insights into the behavior of WW and NWW. In the case of VERG, NWW's susceptibility towards VERG depicted that a graduate NWW were more prone towards VERG influences as compared to a Graduate WW. Overall, the magnitude of the mean scores of education (Table 4) revealed that WW and NWW were insensitive to the influence of VERG (mean scores < than 2) and hence marketers may develop communication messages which simultaneously appeal to all the education levels in a similar fashion while targeting WW and NWW.

Household Income (HI) did show significant differences among WW and NWW. In case of WW, household income refers to the income of the family in addition to her own income while in case of NWW, household income refers to all other sources of income except her own as she isn't a working professional. The output showed rational results (Table 6) for WW where-in HI showed susceptibility towards URG and a WW having $\mathrm{HI}<25 \mathrm{~K}$ was highly vulnerable to conforming with group norms. Similarly, a WW having HI 50K - 1Lac were vulnerable to VERG influence indicating psychological association shown by WW who would want to identify with their referents viz. celebrities and endorsers, which helps in enhancing their selfesteem and self-concept (as explained by Shukla, 2008; Kelman, 1961). WW in the HI bracket show higher need for identifying with people who are admired and respected in the society. 


\section{Contribution}

\section{Theoretical Contribution}

This research attempts to fill the deficiencies in the extant literature on demographic variables impacting RGI. It also contributes by providing empirical evidence in the context of an emerging market India. This would also help academicians to understand consumer behavior of these two segments of WW and NWW. Furthermore, the study on women reference group behavior would contribute to the body of knowledge and would be of utility to academicians to discuss the susceptibility of RGI and its impact on socio-demographic variables. The outcome of the study provides detailed results pertaining to the differences in the influences of Informational / Utilitarian and Value Expressive reference group on WW and NWW across age, education and household income levels. This study has provided a detailed discussion to explain this phenomenon and has advanced into the existing theory with logics and facts. The findings of the study will help understand women behavior and their susceptibility to group influences along with developing newer models of consumer behavior for the women segments.

\section{Managerial Contribution}

Particularly, marketers should gain insights from the socio-economic variables as being factors affecting the susceptibility towards RGIs. They should launch intervention programs catering to every age specially towards mid-age consumers, educational levels and income to gain attention of WW and NWW thereby helping them make scrutinized product choice decisions. The present study indicated that 'mid age' NWW when compared with 'young' WW and 'elderly' WW resp. showed similar behavior towards its susceptibility on IRG, URG and VERG and hence marketers can consider them as a single segment. This implies that no special marketing efforts may be needed to reach the two groups in this case as they could be considered as a part of the organizations target market. The 'young' NWW and 'elderly' WW were susceptible towards VERG and hence marketers could deal with them accordingly to boost their respective self-image and self-concept.

Variations exist between WW and NWW across three educational levels w.r.t its susceptibility towards RGIs. These differences and similarity may be because education impart feelings of self-worth and self-confidence, which are more important features for behavior and social change. Marketers should consider a 'graduate' NWW and WW having educational level 'below $12^{\prime}$ ' as a single segment as they show similarity in their susceptibility towards IRG, URG and VERG. Similarly, Marketers should consider a NWW having qualification '12\&above' and WW having educational level 'below 12' as a single segment as they show similarity in their susceptibility towards IRG, URG and VERG. For these groups, similar communication messages and marketing planning processes could be targeted at them by marketing firms.

It is necessary to point out that the differences among NWW and WW and the three levels of $\mathrm{HI}$ emphasize that $\mathrm{HI}$ is an important indicator for marketers. WW and NWW can be identified by their HI and HI significantly determines the groups purchase intention towards products/services based on the type of influence exerted by RG. Thus, HI categories present valuable criteria for market segmentation. 
So, the demographic variables can enable producers to create different product lines meant for different consumer class WW / NWW. The same can be said for the type of RGI. Furthermore, advertisement messages can be designed to appeal to either WW/NWW or both across age, education and HI. To be positioned in the best possible way, manufacturers and retailers need to be informed about their target markets susceptibility towards RGI which would differ based on the categories of the demographic variables to which they belong to.

The study would facilitate marketers to target socio-demographic as the key variables while planning their marketing strategies. They should target consumers from different age groups, educational levels and of varied household income through advertising commercials emphasizing their susceptibility to social influence to generate more revenue for the product purchases and repeat purchases. Thus, leading to giving more prominence in their advertising strategy towards WW and NWW.

\section{Social Implications}

Social marketing can benefit by using the social reference group influence study to support the understanding of the RGI's impact on the socio-demographic variables. The study explicates the efficacy of identifying various segments which would help the marketing domain. Secondly, the study is first of its kind which brings the concepts of reference groups, socio-demographic variables and the segments of WW and NWW together in a single study considering the importance of this segment in consumer buying behavior among households. Finally, the study is first of its kind to discuss the cross-comparison of the demographic variables like age, education and household income based on their susceptibility to RGI. The research would effectively discourse specific RGI patterns that need to be addressed for the target segments of WW and NWW. The study would help individuals realize that they tend to get influenced by reference groups based on their group membership. The results of the study would help suggest comprehensive advertising and communication messages directed towards IRG, URG and VERG influences for the specific demographic variables across WW and NWW. Appropriate messages can be developed, and media outlets can accordingly be identified to effectively reach the segments that have been identified based on the age, education and income groups to bring to light their behavior towards social influences which would in-turn support marketers identify the right channel to market their product and brand decisions.

\section{Future Scope of Research}

Conspicuousness has been found to be a factor on which group influences differ. There is a scope to study how group influences differ amongst the WW and NWW based on the conspicuousness of products involving conditions of public necessity (PUN), public luxury (PUL), private necessity (PRN) and private luxury (PRL) products. The same can be studied across other demographic variables like age, education, income, marital status etc. Future researchers can suggest studying RGI's in other groups of population and cultures. 


\section{References}

[1] Acharya, D. R., Bell, J. S., Simkhada, P., Van Teijlingen, E. R., \& Regmi, P. R. (2010). Women's autonomy in household decision-making: a demographic study in Nepal. Reproductive health, 7(1), 15.

[2] Arnold, S.J. \& Fischer, E. (1994) Sex, gender identity, gender role attitudes, and consumer behavior. Psychology and Marketing, 11, 163-182. [On-line version], Available at Internet: http://www3.interscience.wiley.com_794 715.

[3] Asch, S.E. (1953). Effects of group pressure upon the modification and distortion of judgements, in D. Cartwright and A. Zander (Eds), Group Dynamics, New York.

[4] Atchley, R. C. (1980). The social forces in later life: An introduction to social gerontology. Wadsworth Publishing Company.

[5] Bartos, R. (1977). The moving target: The impact of women's employment on consumer behavior. Journal of Marketing, (July), 31-38.

[6] Batra, R., Homer, P. M., and Kahle, L. R. (2001). Values, susceptibility to normative influence, and attribute importance weights: A Nomological analysis. Journal of Consumer Psychology, Vol.11, 115-128.

[7] Bearden, W. O. and Etzel, M.J. (1982). Reference group influence on product and brand purchase decisions. Journal of Consumer Research, 183-194.

[8] Brokaw, S. and Lakshman, C. (1995). Cross cultural consumer research in India: a review and analysis, Journal of International Consumer Marketing, Vol. 7 No. 3, pp. 53-80.

[9] Burnkrant, R.E., Cousineau, A. (1975). Informational and normative social influence in buyer behavior. Journal of Consumer Research Vol. 2 (12), 206-214.

[10] Chiang, C.T. and Yu, W.C., 2010. Research of female consumer behavior in cosmetics market case study of female consumers in Hsinchu Area Taiwan. I-Business, 2(4), p.348.

[11] Fernandes, S., \& Londhe, B. R. (2015). Influence of social reference group on buying behavior, a comparative study of working and non WW in Bangalore - A pilot study analysis. Indian Journal of Science and Technology, 8(March), 95-124. http://doi.org/10.17485/ijst/2015/v8iS6/64720

[12] Fernandes, S., \& Londhe, B. R. (2014). Working women and non-working women buying Behavior: influence of social reference groups on the purchase of products - a review. Indian Journal of Commerce and Management Studies, May, Volume V, Issue 2, pp.91-98, www.scholarshub.net

[13] Gabriel, S. and Gardner, W.L. (1999). Are there 'his' and 'hers' types of interdependence? The implications of gender differences in collective versus relational interdependence for affect, behavior, and cognition. Journal of personality and social psychology, Vol. 77, 642-655.

[14] Greco, A. J. (2015). Differences in Susceptibility to Reference Group Influence on Brand Decisions: Middle Aged and Elderly Group Participants. In Proceedings of the 1986 Academy of Marketing Science (AMS) Annual Conference (pp. 46-50). Springer, Cham. 
[15] Holmberg, J. and Öhnfeldt, R., 2010. The female fashion consumer behaviour-From the perspective of the shop Fever in Gothenburg.

[16] Josza, L. (2007). The relative influence of parents and peers on young people's consumer behavior. Journal of Marketing, 2930-2937.Kelman, H. C. (1961). Three processes of social influence. Public Opinion Quarterly, 25, 57-78.

[17] Khan, G., \& Khan, N. (2008). Gender differences in susceptibility to normative social influence on the purchase decisions of designer label apparel. International Business \& Economics Research Journal, 7(8), 11-19.

[18] Kokoi, I. (2011). Female buying behavior related to facial skin care products. LAP Lambert Acad. Publication.

[19] Lessig, V., \& Park, C. (1978). Promotional perspectives of reference group influence: Advertising implications. Journal of Advertising, 7, 41-47. http://doi.org/10.1080/00913367.1978.10673220

[20] Lessig, V., \& Park, C. (1977). Students and NWW: differences in susceptibility to reference group influence. Journal of Consumer Research, 4(2), 102. http://doi.org/10.1086/208685

[21] Maccoby, E.,E. (1990). Gender and relationships: A development account. American psychologist, Vol. 45, 513-520.

[22] Martínez, E., \& Polo, Y. (1999). Determining factors in family purchasing behavior: an empirical investigation. Journal of Consumer Marketing, 16(5), 461-481. http://doi.org/10.1108/07363769910289569

[23] Mehta, S.C., Lalwani, A.K. and Ping, L., 2001. Reference group influence and perceived risk in services among working women in Singapore: A replication and extension. Journal of International Consumer Marketing, 14(1), pp.43-65.

[24] Nair, V. K., \& Pillai, P. R., 2007. A study on purchase pattern of cosmetics among consumers in Kerala. In International Marketing Conference on Marketing \& Society, Vol. 6, No. 1, pp. 581-595.

[25] Palmore, E. B. (1968). The effects of aging on activities and attitudes. The Gerontologist.

[26] Rajagopal, D., 2011. Consumer culture and purchase intentions toward fashion apparel in Mexico. Database Marketing \& Customer Strategy Management, 18(4), pp.286-307.

[27] Schiffman, L. G., \& Kanuk, L. L. (2007). Purchasing behavior.

[28] Shukla, P. (2008). Conspicuous consumption among middle age consumers: psychological and brand antecedents. Journal of Product \& Brand Management, 17(1), 25-36. http://doi.org/10.1108/10610420810856495

[29] Spero, I. and Stone, M. (2004). Agents of change: how young consumers are changing the world of marketing. Qualitative Market Research: an International Journal, Vol. 7, No. 2, pp. 153-9.

[30] Vidyarthi, A., 2014. Factors affecting purchase of necessity brands: the influence of consumer characteristics and global vs local brand perceptions among Indian consumers. 
[31] Terry, D. J., and Hogg, M. A. (1996). Group norms and the attitude-behavior relationship: A role for group identification. Personality and Social Psychology Bulletin, Vol. 22, 776-793

[32] Terry, A. C., \& Rao. (1992). The influence of familail and peer-based reference groups on consumer decisions. Journal of Political Economy, 100(3), 468-505.

[33] Wijesundera, G. and Abeysekera, R. (2010). Factors influencing the demand of beauty soap among female consumers in the greater Colombo Region. University of Kelaniya, Sri Lanka

[34] Xihao, H. \& Yang, J. (2007). Social influence on consumers' purchasing behavior and related marketing strategy -- a cross - nation comparative study. Retrieved April 22, 2016, from http://citeseerx.ist.psu.edu/viewdoc/download?doi=10.1.1.502.6134\&rep=rep1\&type=pdf

[35] Zanoli, R. and Naspetti, S. (2002). Consumer motivations in the purchase of organic food. British Food Journal, Vol. 104 (8/9), 643 